\title{
Multi-locus genetic identification of a newly discovered population reveals a deep genetic divergence in European blind mole rats (Rodentia : Spalacidae : Nannospalax)
}

\author{
Attila Németh ${ }^{1}$, Gábor Csorba ${ }^{1, *}$, Levente Laczkó², Edvárd Mizsei ${ }^{3,4}$, Judit \\ Bereczki $^{5}$, János Attila Pásztor ${ }^{6}$, Péter Petró ${ }^{6} \&$ Gábor Sramkó ${ }^{7}$
}

1) Hungarian Natural History Museum, Baross 13, H-1088 Budapest, Hungary ('corresponding author's e-mail: csorba.gabor@nhmus.hu)

2) Department of Botany, University of Debrecen, Egyetem ter 1, H-4032 Debrecen, Hungary

3) Department of Ecology, University of Debrecen, Egyetem ter 1, H-4032 Debrecen, Hungary

4) DRI Conservation Ecology Research Group, Centre for Ecological Research, Hungarian Academy of Sciences, Bem ter 18/C, H-4026 Debrecen, Hungary

5) Department of Evolutionary Zoology and Human Biology, University of Debrecen, Egyetem ter 1, H-4032 Debrecen, Hungary

6) Nature Conservation Group of 'The friends of Albertirsa' Association, Irsay Karoly 2, H-2730 Albertirsa, Hungary

7) MTA-DE 'Lendület' Evolutionary Phylogenomics Research Group, Egyetem ter 1, H-4032 Debrecen, Hungary

Received 7 Jan. 2020, final version received 1 Apr. 2020, accepted 7 Apr. 2020

Németh. A., Csorba, G., Laczkó, L., Mizsei, E., Bereczki, J., Pásztor J. A., Petró P. \& Sramkó, G. 2020: Multi-locus genetic identification of a newly discovered population reveals a deep genetic divergence in European blind mole rats (Rodentia : Spalacidae : Nannospalax). - Ann. Zool. Fennici 57: 89-98.

A new population of blind mole rat (genus Nannospalax) was discovered near the town of Albertirsa in north-central Hungary. We used newly designed primers to specifically amplify the whole mitochondrial cytochrome- $b$ region and two nuclear DNA regions. Based on the most comprehensive taxonomic sampling to date, we compared this population with several other European blind mole-rat taxa. The results from both mitochondrial and nuclear regions have unequivocally placed the Albertirsa population into the monophyletic group of the Vojvodina blind mole rat ( $N$. (leucodon) montanosyrmiensis), which turned out to be a sister clade to all other molecularly studied European Nannospalax. This study not only identified the fourth known population of an extremely rare rodent taxon but also calls for a taxonomic revision of European lesser blind mole rats ( $N$. leucodon superspecies) to systematically evaluate the genetic structure of their populations and to understand the complex evolutionary history of these European rodents. The occurrence of the Vojvodina blind mole rat at this northern location helps to clarify the distribution area of this heavily data-deficient taxon. As currently understood, this lineage predominantly occurs in sandy grasslands of the Danube-Tisza Interfluve in Hungary and Serbia. Its distribution range and phylogenetic structure might reflect the importance of potential biogeographical barriers (e.g. large rivers) that shaped the blind mole rats' allopatric or peripatric speciation. 


\section{Introduction}

According to the "unified species concept" (de Queiroz 2007), which defines species as "segments of separately evolving metapopulation lineages", all species criteria (i.e., morphological, phylogenetic, ecological, biological, etc.) may appear during the divergence of isolated lineages. Sometimes, the sequence of appearance of these criteria is different or their simple acquisition does not take place during the course of existence of the "separately evolving metapopulation lineages", still, they form species. The lack of morphological difference (i.e., the violation of the phenetic species concept) can lead to the existence of cryptic species, which are defined as "species that remain indistinguishable morphologically" (Bickford et al. 2007). Morphological stasis can easily be a result of stabilising selection posed by extreme environmental conditions if coupled with phylogenetic niche conservatism (i.e., the tendency of a lineage to retain ecological niche over evolutionary time) (Fišer et al. 2018). Genetic isolation between species, as a primary proxy of ongoing speciation (Bock 2004) and the emergence of separately evolving entities, can be best measured by DNA methods (Fišer et al. 2018).

Eurasian blind mole rats (Spalacidae: Spalacinae) form one of the least-known group of Palaearctic rodents. They live a subterranean life that is typical for the whole subfamily, thus, they nicely illustrate phylogenetic niche conservativism that has led to a decreased interspecific morphological variability compared with that in other rodents (Nevo 2000). They can also be typical examples of cryptic species and their systematics - despite more than hundred years of detailed systematic studies (e.g., Nehring 1897, Méhely 1909, Topachevskii 1969, Nevo et al. 2001) - is a source of long-standing disagreement (i.e. Savić \& Nevo 1990, Harrison \& Bates 1991, Musser \& Carleton 2005, Kryštufek \& Vohralík 2009, Norris 2017). The lesser blind mole rat Nannospalax leucodon Nordmann, 1840 superspecies is endemic to Europe and characterised by high chromosomal diversity (Kryštufek \& Vohralík 2009), with 25 karyologically distinct forms reported so far (see Arslan et al. 2016). Although the species status of taxa described in the genus solely on chromosomal grounds has not been widely accepted (Kryštufek 1997, Kryštufek et al. 2012), breeding experiments on several chromosomal forms (Savić \& Soldatović 1984, Savić et al. 2017), corroborated by the results of recent molecular phylogenetic investigations (Hadid et al. 2012, Kryštufek et al. 2012, Németh et al. 2013a), strongly suggest the possibility of the existence of cryptic species status of some of these forms.

From the grasslands of the Pannonian (or Carpathian) Basin four Nannospalax taxa have been described: $N$. (leucodon) transsylvanicus Méhely, 1909; N. (leucodon) hungaricus Nehring, 1898; the most likely extinct $N$. (leucodon) syrmiensis Méhely, 1909 and N. (leucodon) montanosyrmiensis Savić and Soldatović, 1974 (Savić and Soldatović 1984, Németh et al. 2009, Csorba et al. 2015). The latter taxon (the Vojvodina blind mole rat) was originally described on karyological grounds by Savić and Soldatović (1974) as Spalax montanosyrmiensis from two neighbouring localities (Stražilovo and Cortanovci) on the Fruška gora in Vojvodina, Serbia, and proved to be reproductively isolated from other chromosomal forms of Nannospalax in the region (Savić \& Soldatović 1984, Savić et al. 2017). During the research of blind mole rats of the Pannonian Basin, a small and fragmented population of blind mole rats was found in 2008 between Subotica (N Serbia) and Kelebia (S Hungary) (Németh et al. 2013a). Cytogenetic investigations identified the population as $N$. (leucodon) montanosyrmiensis (Németh et al. 2013a). In 2013, another population was discovered near Baja (S Hungary), which, based on molecular phylogenetic studies, also turned out to be $N$. (leucodon) montanosyrmiensis (Csorba et al. 2015).

In April 2017, a new population of blind mole-rats was discovered near Albertirsa (central Hungary). Although several localities were previously reported from this region, blind mole rats were considered extinct in the area because the last occurrence dated back to 1905 (Németh et al. 2009). As a consequence of the lack of observable morphological differences between Hungarian Nannospalax species, we used sequences of cytochrome $b(C Y T B)$ a widely used mitochondrial-DNA (mtDNA) region and 
developed two nuclear regions to (i) identify the Albertirsa population using molecular genetic methods, and (ii) test the phylogenetic resolution of these markers in discriminating between cryptic species of the genus Nannospalax.

\section{Material and methods}

As all taxa of blind mole rats are strictly protected in Hungary, it was permitted to sample only two individuals from the newly discovered Albertirsa population. In May 2017, a male and a female individual were captured using a live-catching method (Németh et al. 2007), and were handled in the field in accordance with guidelines approved by the American Society of Mammalogists (Gannon et al. 2007). After biopsy of hind foot skin matrix applying topical and systemic anaesthesia and 70\% alcohol disinfection following the protocol described by Sós et al. (2009), both individuals were immediately released at the site of capture back into their tunnel system. Samples from other populations in the Pannonian Basin and outgroup taxa were collected between 2008 and 2017 following the same protocol. Tissue samples were stored in $96 \%$ ethanol at $-20{ }^{\circ} \mathrm{C}$ and housed in the Hungarian Natural History Museum until analysed.

Genomic DNA was extracted as detailed in Cserkész et al. (2017). The mitochondrionencoded CYTB was amplified using de novo designed primers (SpalaxCBfw2: 5'-TGA CAT GAA AAA TCA TCG-3'; SpalaxCBrv2: 5'-CGA GAA GAG AGG TAC TA-3') based on publicly available sequences of Nannospalax carmeli (GenBank accession number: NC_020756) and Nannospalax ehrenbergi (GenBank accession number: AJ416891). As a single gene can be misleading in identification and because of the common occurrence of mito-nuclear discordance via hybridisation (Toews \& Brelsford 2012), the sequence information of the maternally inherited (mitochondrial) gene was supplemented with two nuclear-DNA (nDNA) regions using specific primers designed here for the first time. We amplified and sequenced fragments of two nuclear coding genes, the LecithinCholesterol Acyltransferase (LCAT) gene and the Interphotoreceptor Retinoid Binding Protein
(IRBP). The first fragment of $L C A T$ was amplified using primers LCAT1 $\mathrm{fw}$ ( $5^{\prime}$-GGA CTT CTT CAC CAT CTG GC-3') and LCAT1rv ( $5^{\prime}$-AGG TTG ATG CAG TAA GAA ATA GAG C-3'), whereas primers LCAT3fw (5'-CGC ATA ACG ACG ACT TCT CC-3') and LCAT3rv (5'-ATG TTG AGG TGT TGT GTC CC-3') were used to amplify the second fragment; both primer pairs were designed based on genomic sequence of Nannospalax galili (GenBank accession number: NW 008343085). The coding gene IRBP was amplified and sequenced using primers SpalaxIRBPfw (5'-ATG ATG AGA CAA TGG CTC CTG C-3') and SpalaxIRBPrv (5'-TGA GGT GCT CTG TGT TCT GC-3') designed based on available sequences of Spalax zemni (GenBank accession number: U48589) and Nannospalax ehrenbergi (GenBank accession number: JN414825). Polymerase Chain Reactions (PCRs) were performed in $25 \mu \mathrm{l}$ volume using $1 \times$ Reaction Buffer (Thermo Scientific), $0.2 \mathrm{mM}$ of each dNTP (Thermo Scientific), $2 \mathrm{mM} \mathrm{MgCl}_{2}$ (Thermo Scientific), $0.25 \mathrm{mg}$ Bovine Serum Albumin (Invitrogen), $0.2 \mu \mathrm{M}$ of each primer, $0.03 \mathrm{U}$ of Phusion II Hot Start Polymerase (Thermo Scientific), and $1 \mu$ unquantified DNA template. PCR conditions for $C Y T B$ were: initial denaturation for $3 \mathrm{~min}$ at $98{ }^{\circ} \mathrm{C}$ followed by 40 cycles of denaturation for $10 \mathrm{sec}$ at $98^{\circ} \mathrm{C}$, $30 \mathrm{sec}$ annealing at $57^{\circ} \mathrm{C}, 1 \mathrm{~min} 30 \mathrm{sec}$ extension at $72{ }^{\circ} \mathrm{C}$, and final extension for $7 \mathrm{~min}$ at $72{ }^{\circ} \mathrm{C}$. For the LCAT fragments, this cycling was modified by setting annealing temperature to $62{ }^{\circ} \mathrm{C}$ and extension time to $1 \mathrm{~min}$. The $I R B P$ gene was amplified using the same cycling as described for $C Y T B$, except annealing temperature set to $60{ }^{\circ} \mathrm{C}$. Sequences were checked for errors and aligned by MUSCLE ver. 3.8.31 (Edgar 2004). All newly generated sequences were deposited in GenBank (Table 1; GenBank accession numbers: MN497962-MN498009).

We compiled a data set of newly generated $C Y T B$ and two nuclear gene sequences covering all known taxa and populations of Nannospalax from the Pannonian Basin (Table 1 and Fig. 1), most of which have never been studied in terms of molecular phylogeny. In the analyses we included sequences published in the most comprehensive phylogenetic study of European Nannospalax to date (Kryštufek et al. 2012) in 


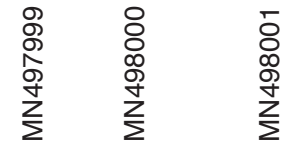

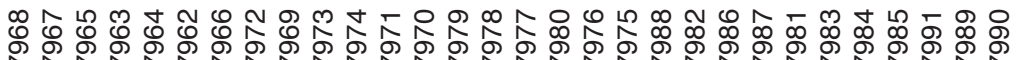

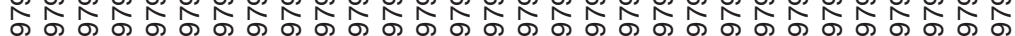

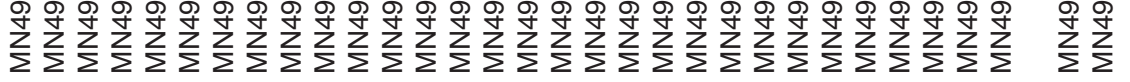

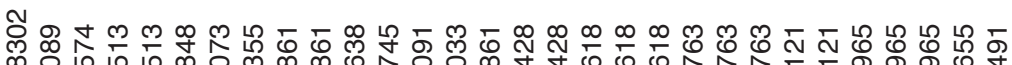

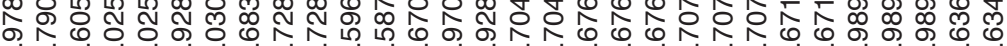

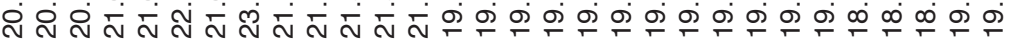

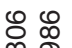
我 8 iें

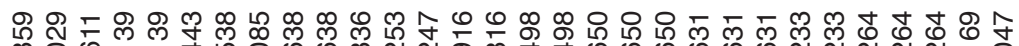
N

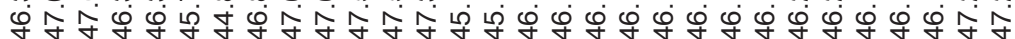

누 守 㐫字

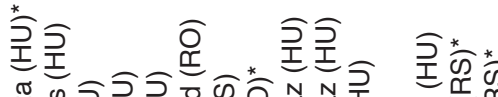

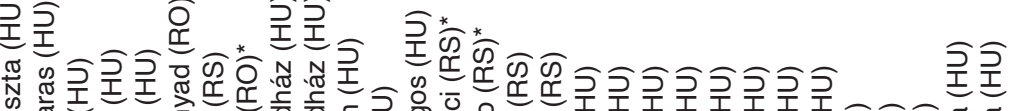

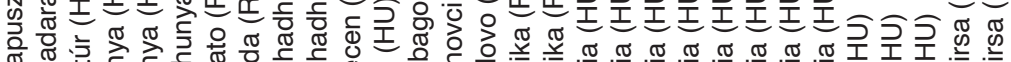

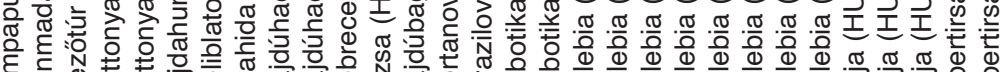

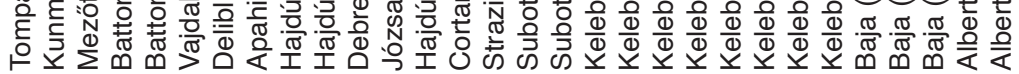

\section{হু হু 年} म ब

$\frac{\sqrt{8}}{\frac{\pi}{\pi}}$ 
Fig. 1. Approximate distribution and location of the studied populations of blind mole-rats in the Carpathian Basin. Main rivers are shown in blue. Triangles in the upper left inset indicate locations of samples included as outgroups. * extinct taxon/ population.

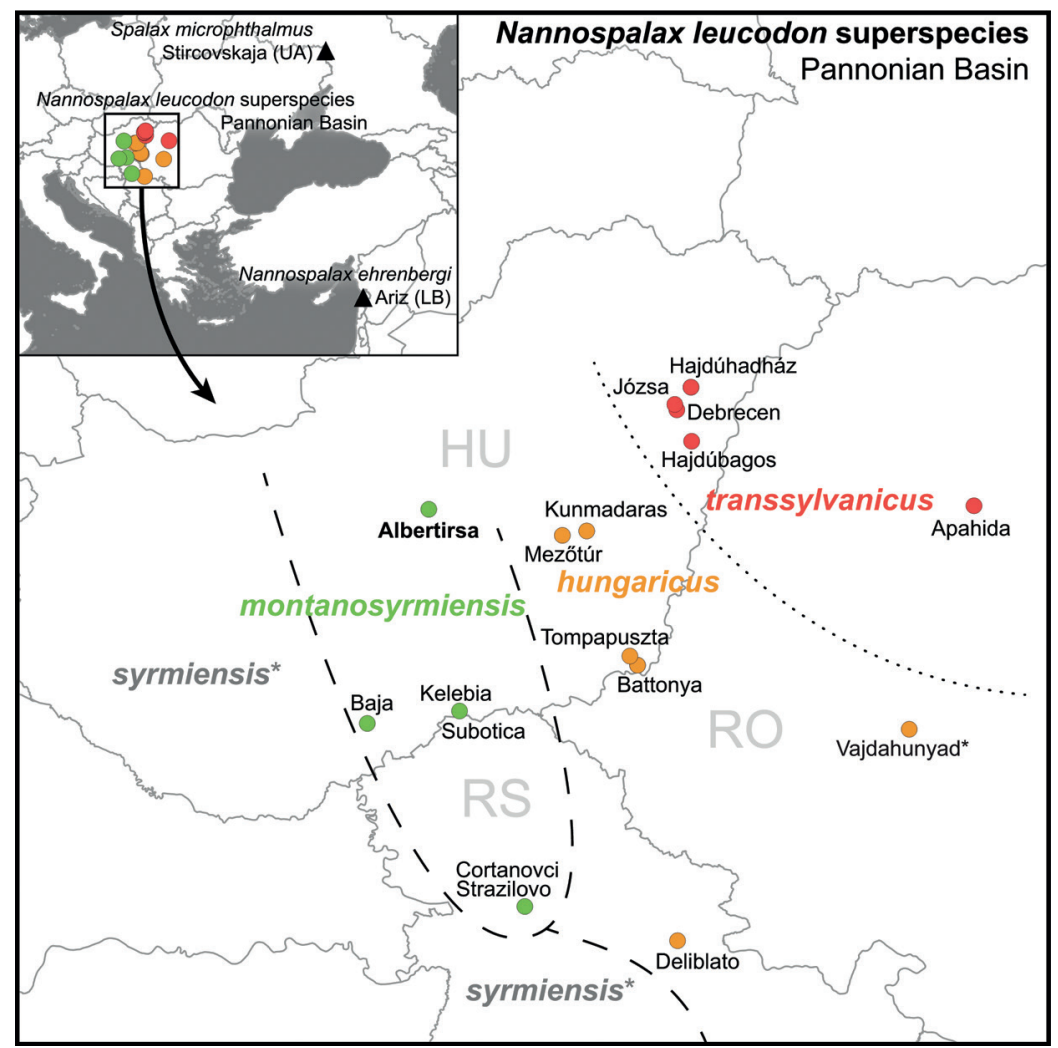

our CYTB data set (GenBank accession numbers JX451833-JX451848) to place our results into a comprehensive phylogenetic context.

In our first analysis, we selected eight populations to represent each taxon of the Pannonian Basin (Fig. 1) each of which included two individuals (Table 1), except for the outgroup taxa and $N$. (leucodon) transsylvanicus, for which only single individuals were included in the nuclear ( $L C A T$ and IRBP) data set. To investigate genetic distances between the samples, neighbour-networks (Bryant \& Moulton 2004) were reconstructed separately for each locus using the Kimura-2-parameter genetic distance matrix as implemented in SplitsTree ver. 4.14.4. (Huson \& Bryant 2006). Branch support values were assessed by applying 1000 bootstrap replications.

A phylogenetic reconstruction was based on CYTB sequences using both maximum likelihood and Bayesian approaches. Maximum likelihood (ML) phylogenetic tree reconstruction was performed using PhyML ver. 3.0. (Guindon et al. 2010) with smart model selection (SMS) turned on (Lefort et al. 2017). As outgroups, we sequenced Spalax microphtalmus and Nannospalax ehrenbergi (Table 1), with the inclusion of CYTB sequence of $N$. (ehrenbergi) carmeli (GenBank: NC_020756). To assess branch support values, an approximate likelihood ratio test (aLRT) was applied in the ML search. Bayesian phylogenetic reconstruction was performed using MrBayes ver. 3.2.7 (Ronquist et al. 2012), where the GTR $+\mathrm{G}+$ I nucleotide substitution model was applied, which was found by SMS as the best model of sequence evolution for this dataset. This analysis was run for 25 million generations sampling every 10 000th step after which convergence and effective sample sizes were checked using Tracer ver. 1.6 (Rambaut et al. 2014).

\section{Results}

The primers for the $C Y T B$ region yielded $1604 \mathrm{bp}$ long sequences that include the entire CYTB gene from position 14151 to $15290 \mathrm{bp}$ 


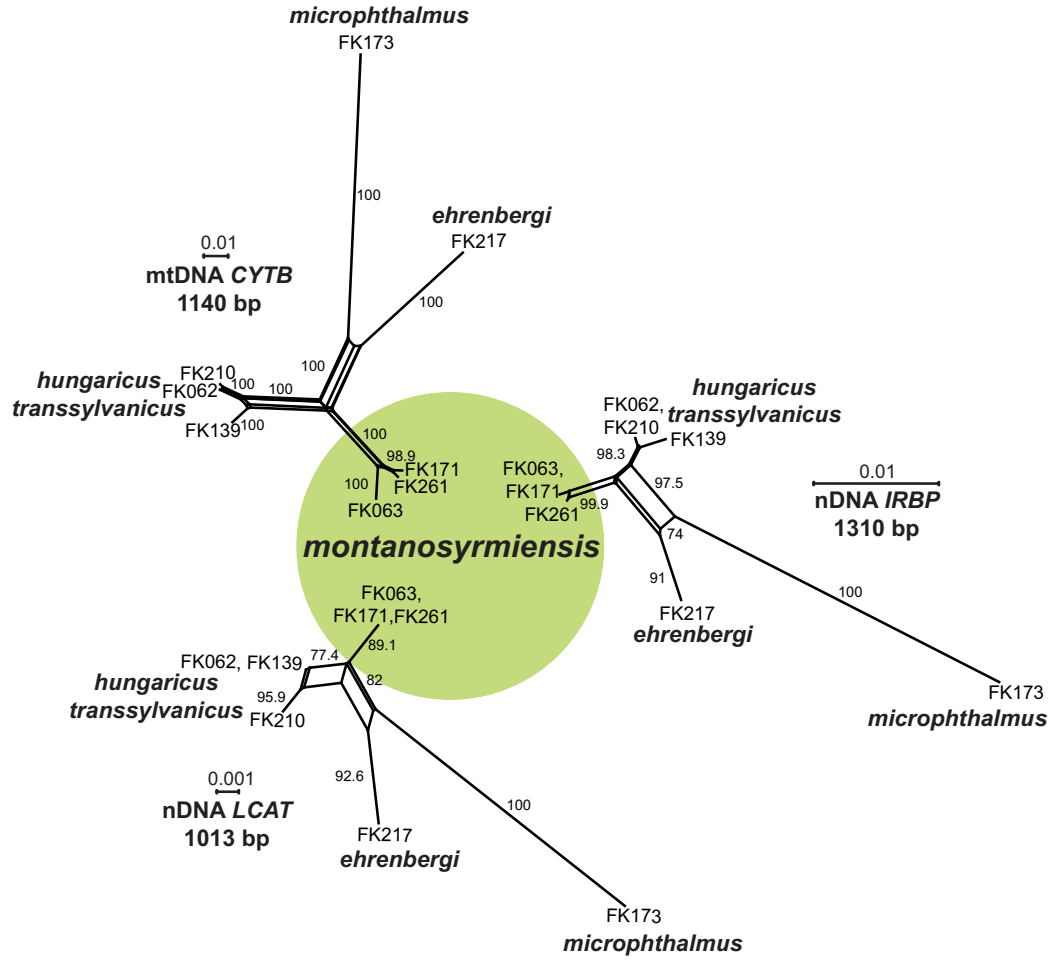

Fig. 2. Neighbour-joining networks of one mtDNA (CYTB) and two nDNA ( $L C A T$ and IRBP) genes of blind mole-rats in the Pannonian Basin and outgroups (N. ehrenbergi, S. microphthalmus). in AJ416891 and the $5^{\prime}$ part of the control region from position 15291 to 15749 in AJ416891. In the current analyses, only the 1140-bp-long CYTB region was used. The new primers for the amplification and sequencing of the first fragment of the LCAT region yielded 630-bplong sequences that included (compared with the reference sequence of AH005252) the partial first exon (incomplete at $5^{\prime}$ end), three complete introns and two complete exon regions, plus a near complete fourth exon (incomplete at $3^{\prime}$ end). The second fragment of the LCAT region produced 370 -bp-long reads that covered the fifth exon (incomplete at both ends) of the gene. For the downstream analysis of this gene region, we concatenated the above two non-overlapping fragments which contained no double-peaks (i.e., sign of heterozygote state) in the electropherograms. The new primers for the amplification and sequencing of the IRBP gene produced 1305 bp long sequences that covered a large proportion of the $3^{\prime}$ part of the IRBP gene (as compared with the XM_008834127 sequence as reference) but it was incomplete at both ends. Again, our sample set did not contain signs of the presence of different alleles (i.e., double-peaks in the electropherograms) in this diploid marker.

Neighbor networks of CYTB, LCAT and IRBP placed the samples from the newly discovered population of Albertirsa in the monophyletic group of $N$. (leucodon) montanosyrmiensis with high statistical support (Fig. 2). Based on our results it is unlikely that the Albertirsa population is a hybrid between $N$. (leucodon) montanosyrmiensis and $N$. (leucodon) hungaricus. The latter one, however, based on cranial and dental traits was previously reported from some nearby localities by Méhely (1909). The phylogenetic analyses of the mitochondrial CYTB gene sequences also placed the two individuals from the Albertirsa population within the well-supported (ML aLRT: 0.99; Bayesian inference posterior probability (PP): 1.0) lineage of $N$. (leucodon) montanosyrmiensis (Fig. 3). The assignment of this lineage to this taxon is confirmed by the inclusion of two individuals (FK099 and FK106) from the type locality of $N$. (leucodon) montanosyrmiensis.

The phylogenetic tree reconstruction based on the ML and Bayesian inference (BI) criteria 


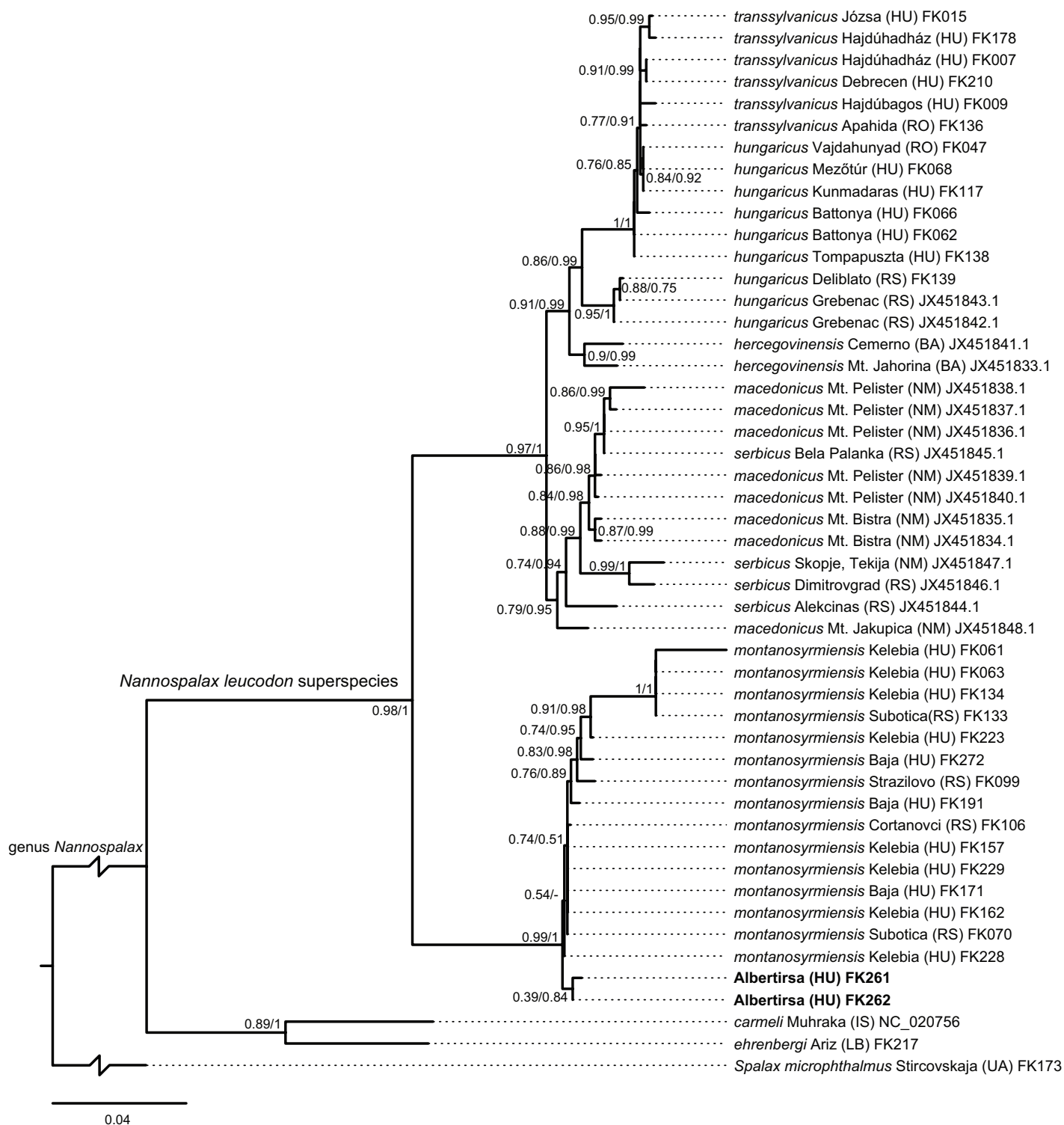

Fig. 3. Phylogenetic relationships of European Nannospalax species based on all currently available whole CYTB region sequences. The tree is a phylogram coming from a maximum likelihood tree reconstruction in PhyML-SMS. A phylogenetic tree with similar topology was recovered using the Bayesian inference. Support values (at the nodes) based on the approximate likelihood ratio test in PhyML followed by Bayesian posterior probability values assessed by MrBayes after a slash.

identified the best phylogenetic trees with the same topology. Surprisingly, the phylogenetic reconstructions showed a well-supported (ML aLRT: 0.98; BI PP: 1.0) split between Nannospalax from the Pannonian Basin and the Balkan Peninsula, where N. (leucodon) montanosyrmiensis forms a sister lineage to all other studied blind mole rats (Fig. 3). The proper systematic evaluation of this unexpectedly deep (i.e., genetically distant) split would only be possible with the inclusion of topotypic material representing other European chromosomal forms and other lineages of the genus regarded as superspecies (i.e., Anatolian N. xanthodon). However, the branch leading to $N$. (leucodon) montanosyrmiensis is comparable in length to the one leading 
to all other remaining sampled taxa and also to the branch leading to the two outgroup samples.

It is also worth noting the phylogenetic position of Nannospalax (leucodon) hungaricus and $N$. (leucodon) transsylvanicus samples in our network (Fig. 2) and on our phylogenetic tree (Fig. 3). The sample of $N$. (leucodon) hungaricus from Serbia (FK139) shows divergence from the sample of the supposedly same species from Hungary (FK062). In turn, this latter sample shares the same DNA sequences in the nuclear region $I R B P$ with the sample of $N$. (leucodon) transsylvanicus (FK210) (Fig. 2). This structure is even more clearly expressed on the phylogenetic tree more densely sampled for mitochondrial CYTB (Fig. 3) where the Serbian samples form a monophyletic group diverged from the sister-lineage composed of samples of Hungarian samples of $N$. (leucodon) hungaricus and Hungarian and Romanian N. (leucodon) transsylvanicus. Such a relatively deep split, which is comparable to splits between geographically distinct group of taxa within the genus, hints at taxonomic instability of the taxa involved, and their taxonomic position warrants further, more detailed research.

\section{Discussion}

The identification of the Albertirsa population as $N$. (leucodon) montanosyrmiensis helps to understand the distributional patterns of the taxon, which is currently data deficient and worryingly threatened by extinction (Csorba et al. 2015). The first population discovered was found in the southernmost part of its area, as currently understood, at the northeastern slopes of the Fruška gora (Stražilovo and Čortanovci) (Fig. 1). Further to the south and the west, it is replaced by another chromosomal form of the $N$. leucodon superspecies, namely the possibly extinct $N$. (leucodon) syrmiensis (Savić \& Soldatović 1984). Until recently, only two additional populations of $N$. (leucodon) montanosyrmiensis were known from southern Hungary and northern Serbia. With the discovery of the fourth population, the known distribution of the taxon has expanded considerably northwards and now includes the northern part of the Kiskunság Sand
Ridge, an important forest-steppe area of Hungary (Erdős et al. 2014, Bátori et al. 2018). The present finding raises the possibility that the taxon was once widely distributed in the large territory between the Danube and Tisza rivers in Hungary and Serbia but is nowadays restricted to isolated patches of remnant steppes. The historical presence of $N$. (leucodon) hungaricus in regions further north suggests that Albertirsa might define the northern limit of the Vojvodina blind mole rat's distribution.

Species of Spalacinae can hardly cross large rivers, therefore, such a barrier can easily trigger allopatric divergence (Pyron \& Burbrink 2010); moreover, all taxa with unique chromosomal arrangement investigated so far are known to be reproductively isolated from the neighbouring taxa (Savić \& Soldatović 1984, Savić et al. 2017). Geographic barriers, especially large rivers are known to be effective barriers for animal species with a reduced mobility and can have an isolating effect on populations (e.g., Trizio et al. 2005, Kennis et al. 2011) and species (e.g. Tóth et al. 2019). For example, the effective isolation of European ground-squirrel (Spermophilus citellus) populations was observed by Ćosić et al. (2013) in the southern part of the Danube-Tisza Interfluve. This model of allopatric speciation should be further studied in European blind mole rats of the genus Nannospalax as was undertaken in Israeli species of Nannospalax (Nevo 1982, Nevo et al. 2001). In Spalax species, it is known that the Carpathians (Németh et al. 2013b) and large rivers like Dnieper (Topachevskii 1969, Zagorodniuk et al. 2018) play important role in the speciation processes. The long-awaited taxonomic revision of $N$. leucodon superspecies could serve as a firm base for evolutionary mechanisms to be revealed, which resulted in the extreme karyotypic variability of this group of European rodents.

The combination of the novel markers reported here can effectively distinguish between morphologically indistinguishable cryptic species of the Nannospalax leucodon superspecies (Fig. 2) and holds promise to be used on a larger scale to identify species-level taxonomic units within this group of rodents. Notably, if phylogenetic analyses of these markers can be combined with species-delimitation methods (see Fišer et 
al. 2018), one can then begin to objectively assess species boundaries in this group with several supposed cryptic species. Our case study can serve as a first step towards the understanding of the diversity of European lesser blind mole rats.

\section{Acknowledgements}

We thank the Hungarian and Serbian nature conservation authorities, the Department of Environmental Protection and Nature Conservation of the Government Office for Pest County, Kiskunság and Duna-Ipoly National Park Directorates and the Institute for Nature Conservation of Vojvodina Province for providing permits (14/1840-3/2008, 14/014399/2012, PE-KTF/5215-22/2017) and for their various supports during our field work. We are very grateful to David Michael Scantlebury for his comments and linguistic corrections. Part of the work reported in this study is linked to and was developed within the frame of the LIFE IP project supported by the grant LIFE 17 IPE/HU/000018.

\section{References}

Arslan, A., Kryštufek, B., Matur, F. \& Zima, J. 2016: Review of chromosome races in blind mole-rats (Spalax and Nannospalax). - Folia Zoologica 65: 249-301.

Bátori, Z., Erdős, L., Kelemen, A., Deák, B., Valkó, O., Gallé, R., Bragina, T.M., Kiss, J.P., Kröel-Dulay, Gy. \& Tölgyesi, C. 2018: Diversity patterns in sandy foreststeppes: a comparative study from the western and central Palaearctic. - Biodiversity and Conservation 27: 1011-1030.

Bickford, D., Lohman, D. J., Sodhi, N. S., Ng, P. K. L., Meier, R., Winker, K., Ingram, K. K. \& Das, I. 2007: Cryptic species as a window on diversity and conservation. - Trends in Ecology and Evolution 22: 148-155.

Bock, W. J. 2004: Species: The concept, category and taxon. - Journal of Zoological Systematics and Evolutionary Research 42: 178-190.

Bryant, D. \& Moulton, V. 2004: Neighbor-net: an agglomerative method for the construction of phylogenetic networks. - Molecular Biology and Evolution 21: 255-265.

Ćosić, N., Říčanová, Š., Bryja, J., Penezić, A. \& Ćirović, D. 2013: Do rivers and human-induced habitat fragmentation affect genetic diversity and population structure of the European ground squirrel at the edge of its Pannonian range? - Conservation Genetics 14: 345-354.

Cserkész, T., Fülöp, A., Almerekova, S., Kondor, T., Laczkó, L. \& Sramkó, G. 2017: Phylogenetic and morphological analysis of birch mice (genus Sicista, family Sminthidae, Rodentia) in the Kazak Cradle with description of a new species. - Journal of Mammalian Evolution 26: 147-163.

Csorba, G., Krivek, G., Sendula, T., Homonnay, Z. G.,
Hegyeli, Zs., Sugár, Sz., Farkas, J., Stojnić, N. \& Németh, A. 2015: How can scientific research change conservation priorities? - A review of decade-long research on blind mole-rats (Rodentia: Spalacinae) in the Carpathian Basin. - Therya 6: 103-121.

de Queiroz, K. 2007: Species concepts and species delimitation. - Systematic Biology 56: 879-886.

Edgar, R. C. 2004: MUSCLE: Multiple sequence alignment with high accuracy and high throughput. Nucleic Acids Research 32: 1792-1797.

Ellerman, J. R. \& Morrison-Scott, T. C. S. 1951: Checklist of Palaearctic and Indian mammals, 1758-1946. — British Museum (Natural History), London.

Erdős, L., Tölgyesi, C., Cseh, V., Tolnay, D., Cserhalmi, D., Körmöczi, L., Gellény, K. \& Bátori, Z. 2015: Vegetation history, recent dynamics and future prospects of a Hungarian sandy forest-steppe reserve: forest-grassland relations, tree species composition and size-class distribution. - Community Ecology 16: 95-105.

Fišer, C., Robinson, C. T. \& Malard, F. 2018: Cryptic species as a window into the paradigm shift of the species concept. - Molecular Ecology 27: 613-635.

Gannon, W. L. \& Sikes, R. S. 2007: Guidelines of the American Society of Mammalogists for the use of wild mammals in research. - Journal of Mammalogy 88: 809-823.

Guindon, S., Dufayard, J. F., Lefort, V., Anisimova, M., Hordijk, W. \& Gascuel, O. 2010: New algorithms and methods to estimate maximum-likelihood phylogenies: assessing the performance of PhyML 3.0. - Systematic Biology 59: 307-321.

Hadid, Y., Németh, A., Snir, S., Pavlíček, T., Csorba, G., Kázmér, M., Major, Á., Mezhzherin, S., Rusin, M., Coskun, Y. \& Nevo, E. 2012: Is evolution of blind mole-rats determined by climate oscillations? - PLoS ONE 7(1): e30043, https://doi.org/10.1371/journal.pone. 0030043

Harrison, D. L. \& Bates, P. J. J. 1991: The mammals of Arabia, vol. 357. - Harrison Zoological Museum, Sevenoaks, Kent.

Huson, D. H. \& Bryant, D. 2006: Application of phylogenetic networks in evolutionary studies. - Molecular Biology and Evolution 23:254-267.

Kennis, J., Nicolas, V., Hulselmans, J., Katuala, P. G. B., Wendelen, W., Verheyen, E., Dudu, A. M. \& Leirs, H. 2011: The impact of the Congo River and its tributaries on the rodent genus Praomys: speciation origin or range expansion limit? - Zoological Journal of the Linnean Society 163: 983-1002.

Kryštufek, B. 1997: Overlooked names for European mammals. — Folia Zoologica 46: 91-93.

Kryštufek, B. \& Vohralík, V. 2009: Mammals of Turkey and Cyprus: Rodentia II: Cricetinae, Muridae, Spalacidae, Calomyscidae, Capromydae, Hystricidae, Castoridae. — Znanstveno-raziskovalno središče, Založba Annales, Univerza na Primorskem.

Kryštufek, B., Ivanitskaya, E., Arslan, A., Arslan, E. \& Bužan, E. V. 2012: Evolutionary history of mole-rats (genus Nannospalax) inferred from mitochondrial cytochrome $b$ sequence. - Biological Journal of the 
Linnean Society 105: 446-455.

Lefort, V., Longueville, J.-E. \& Gascuel, O. 2017: SMS: Smart model selection in PhyML. - Molecular Biology and Evolution 34: 2422-2424.

Méhely, L. 1909: Species generis Spalax. A földi kutyák fajai származás- és rendszertani tekintetben. - Magyar Tudományos Akadémia, Budapest.

Musser, G. G. \& Carleton, M. D. 2005: Superfamily Muroidea. - In: Wilson, D. E. \& Reeder, D. M. (eds.) Mammal species of the world: A taxonomic and geographic reference, 3rd ed.: 894-1531. The Johns Hopkins University Press, Baltimore, Maryland.

Nehring, A. 1897: Mehrere neue Spalax-Arten. - Sitzungberichte der Berlinischen Gesellschaft Naturforschender Freunde 10: 163-183.

Németh, A., Czabán, D., Csorba, G. \& Farkas, J. 2007: Evaluating the methods for live-trapping of the Hungarian lesser blind mole-rat (Spalax leucodon). - Természetvédelmi Közlemények 13: 439-444. [In Hungarian with English abstract].

Németh, A., Krnács, G., Krizsik, V., Révay, T., Czabán, D., Stojnić, N., Farkas, J. \& Csorba, G. 2013a: European rodent on the edge: status and distribution of the Vojvodina blind mole-rat. - SpringerPlus 2(1), https://doi. org/10.1186/2193-1801-2-2.

Németh, A., Homonnay, Z. G., Krizsik, V., Csorba, M., Pavlicek, T., Hegyeli, Zs., Hadid, Y., Sugár, Sz., Farkas, J. \& Csorba, G. 2013b: Old views and new insigths - taxonomic revision of the Bukovina blind mole-rat, Spalax graecus (Rodentia: Spalacidae). — Zoological Journal of the Linnean Society 169: 903-914.

Németh, A., Révay, T., Hegyeli, Z., Farkas, J., Czabán, D., Rózsás, A. \& Csorba, G. 2009: Chromosomal forms and risk assessment of Nannospalax (superspecies leucodon) (Mammalia: Rodentia) in the Carpathian Basin. — Folia Zoologica 58: 349-361.

Nevo, E. 1982: Speciation in subterranean mammals. - In: Barigozzi, C. (ed.), Mechanisms of speciation: 191-218. Progress in Clinical and Biological Research 96, Alan R. Liss, Inc., New York.

Nevo, E. 2000: Mosaic evolution of subterranean mammals: Regression, progression, and global convergence. Oxford University Press, Oxford.

Nevo, E., Ivanitskaya, E. \& Beiles, A. 2001: Adaptive radiation of blind subterranean mole-rats: naming and revisiting the four sibling species of the Spalax ehrenbergi superspecies in Israel: Spalax galili $(2 n=52), S$. golani $(2 n=54)$, S. carmeli $(2 n=58)$ and $S$. judaei $(2 n=60)$. - Backhuys Publishers, Leiden.

Norris, R. W. 2017: Family Spalacidae (muroid mole-rats). - In: Wilson, D. E., Lacher, T. E. \& Mittermeier, R. A. (eds.), Handbook of the mammals of the world, vol. 7: Rodents II: 108-142 Lynx Edicions, Barcelona.

Pyron, R. A. \& Burbrink, F. T. 2010: Hard and soft allopatry: physically and ecologically mediated modes of geographic speciation. - Journal of Biogeography 37:
2005-2015.

Rambaut, A., Drummond, A. J., Xie, D., Baele, G. \& Suchard, M. A. 2018: Posterior summarisation in Bayesian phylogenetics using Tracer 1.7. - Systematic Biology 67: 901-904.

Ronquist, F., Teslenko, M., van der Mark, P., Ayres, D. L., Darling, A., Höhna, S., Larget, B., Liu, L., Suchard, M. A. \& Huelsenbeck, J. P. 2012: MrBayes 3.2: Efficient bayesian phylogenetic inference and model choice across a large model space. - Systematic Biology 61: 539-542.

Savić, I., Ćirović, D. \& Bugarski-Stanojević, V. 2017: Exceptional chromosomal evolution and cryptic speciation of blind mole-rats Nannospalax leucodon (Spalacinae, Rodentia) from south-eastern Europe. - Genes 8(11): 292, https://doi.org/10.3390/genes8110292.

Savić, I. R. \& Nevo, E. 1990: The Spalacidae: evolutionary history, speciation, and population biology. - In: Nevo, E. \& Reig, A. O. (eds.), Evolution of subterranean mammals at the organismal and molecular levels: 129-153. Alan R. Liss, New York, New York.

Savić, I. R. \& Soldatović, B. 1974: Die Verbreitung der Karyotypen der Blindmaus Spalax (Mesospalax) in Jugoslavien. - Arhiv Bioloskih Nauka 26: 115-122.

Savić, I. R. \& Soldatović, B. 1984: Karyotype evolution and taxonomy of the genus Nannospalax Palmer 1903, Mammalia, in Europe. - Separate edition of the Serbian Academy of Science and Arts, Beograd.

Sós, E., Molnár, V., Révay, T., Németh, A., Farkas, J., Hidas, A. \& Csorba, G. 2009: Veterinarian participation at the critically endangered lesser blind mole-rat (Nannospalax leucodon) research in Hungary. - In: Proceedings of the International Conference on Diseases of Zoo and Wild Animals, Beekse Bergen, The Netherlands, 20th24th May 2009: 118-121. Leibniz Institute for Zoo and Wildlife Research.

Topachevskii, V. A. 1969: Fauna of the USSR: Mammals: Mole rats: Spalacidae. - Smithsonian Institution and the National Science Foundation, Washington, DC.

Toews, D. P. \& Brelsford, A. 2012: The biogeography of mitochondrial and nuclear discordance in animals. Molecular Ecology 21: 3907-3930.

Tóth, J. P., Bereczki, J., Rácz, R., Varga, Z., Barta, Z. \& Sramkó, G. 2019: Phylogenetic relationships in the genus Lethrus (Coleoptera: Geotrupidae) reveal contrasting evolutionary history in Europe. - Systematic Entomology 44: 899-910.

Trizio, I., Crestanello, B., Galbusera, P., Wauters, L. A., Tosi, G., Matthysen, E. \& Hauffe, H. C. 2005: Geographical distance and physical barriers shape the genetic structure of Eurasian red squirrels (Sciurus vulgaris) in the Italian Alps. - Molecular Ecology 14: 469-481.

Zagorodniuk, I., Korobchenko, M., Parkhomenko, V. \& Barkaszi, Z. 2018: Steppe rodents at the edge their range: a case study of Spalax microphthalmus in the north of Ukraine. - Biosystems Diversity 26: 188-200. 